\title{
25-Hydroxyvitamin D concentration and all-cause mortality: the Melbourne Collaborative Cohort Study
}

\author{
Alicia K Heath ${ }^{1,2}$, Elizabeth J Williamson ${ }^{3,4}$, David Kvaskoff ${ }^{5}$, Allison M Hodge ${ }^{2}$, Peter R \\ Ebeling $^{6}$, Laura Baglietto 1,2,7,8, Rachel E Neale ${ }^{9}$, Graham G Giles ${ }^{1,2}$, Darryl W Eyles 5,10 \\ and Dallas R English ${ }^{1,2, *}$ \\ ${ }^{1}$ Centre for Epidemiology and Biostatistics, Melbourne School of Population and Global Health, The University of \\ Melbourne, Level 3, 207 Bouverie Street, Melbourne, Victoria 3010, Australia: ${ }^{2}$ Cancer Epidemiology Centre, \\ Cancer Council Victoria, Melbourne, Victoria, Australia: ${ }^{3}$ Farr Institute of Health Informatics Research, London, UK: \\ ${ }^{4}$ Department of Medical Statistics, London School of Hygiene \& Tropical Medicine, London, UK: ${ }^{5}$ Queensland Brain \\ Institute, The University of Queensland, St Lucia, Queensland, Australia: ${ }^{6}$ Department of Medicine, School of Clinical \\ Sciences, Monash University, Clayton, Victoria, Australia: ${ }^{7}$ Université Paris-Saclay, Université Paris-Sud, UVSQ, \\ CESP, INSERM, Villejuif, France: ${ }^{8}$ Institut Gustave Roussy, Villejuif, France: ${ }^{9}$ Population Health Division, QIMR \\ Berghofer Medical Research Institute, Brisbane, Queensland, Australia: ${ }^{10}$ Queensland Centre for Mental Health \\ Research, The Park Centre for Mental Health, Wacol, Queensland, Australia
}

Submitted 21 July 2015: Final revision received 1 February 2016: Accepted 15 February 2016: First published online 29 March 2016

\begin{abstract}
Objective: To investigate relationships between mortality and circulating 25-hydroxyvitamin D (25(OH)D), 25-hydroxycholecalciferol $\left(25(\mathrm{OH}) \mathrm{D}_{3}\right)$ and 25-hydroxyergocalciferol $\left(25(\mathrm{OH}) \mathrm{D}_{2}\right)$.

Design: Case-cohort study within the Melbourne Collaborative Cohort Study (MCCS). We measured $25(\mathrm{OH}) \mathrm{D}_{2}$ and $25(\mathrm{OH}) \mathrm{D}_{3}$ in archived dried blood spots by LC-MS/MS. Cox regression was used to estimate mortality hazard ratios (HR), with adjustment for confounders.

Setting: General community.

Subjects: The MCCS included 29206 participants, who at recruitment in 1990-1994 were aged 40-69 years, had dried blood spots collected and no history of cancer. For the present study we selected participants who died by 31 December 2007 ( $n$ 2410) and a random sample (sub-cohort, $n$ 2996).

Results: The HR per $25 \mathrm{nmol} / \mathrm{l}$ increment in concentration of $25(\mathrm{OH}) \mathrm{D}$ and $25(\mathrm{OH}) \mathrm{D}_{3}$ were 0.86 (95\% CI $0.78,0.96 ; P=0.007)$ and 0.85 (95\% CI $0.77,0.95 ; P=0.003$ ), respectively. Of 5108 participants, sixty-three $(1.2 \%)$ had detectable $25(\mathrm{OH}) \mathrm{D}_{2}$; their mean 25(OH)D concentration was 11.9 (95\% CI 7.3, 16.6) nmol/1 higher $(P<0 \cdot 001)$. The HR for detectable $25(\mathrm{OH}) \mathrm{D}_{2}$ was 1.80 (95\% CI 1.09, 2.97; $P=0.023$ ); for those with detectable $25(\mathrm{OH}) \mathrm{D}_{2}$, the HR per $25 \mathrm{nmol} / 1$ increment in $25(\mathrm{OH}) \mathrm{D}$ was 1.06 (95\% CI 0.87, 1.29; $P$ interaction $=0.02)$. HR were similar for participants who reported being in good, very good or excellent health four years after recruitment. Conclusions: Total $25(\mathrm{OH}) \mathrm{D}$ and $25(\mathrm{OH}) \mathrm{D}_{3}$ concentrations were inversely associated with mortality. The finding that the inverse association for $25(\mathrm{OH}) \mathrm{D}$ was restricted to those with no detectable $25(\mathrm{OH}) \mathrm{D}_{2}$ requires confirmation in populations with higher exposure to ergocalciferol.
\end{abstract}

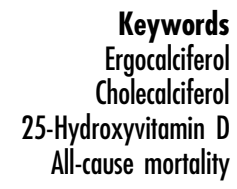

Keywords

Ergocalciferol 5-Hydroxyvitamin D All-cause mortality
Many cohort studies have reported inverse associations between circulating 25-hydroxyvitamin D (25(OH)D) and mortality ${ }^{(1)}$. Vitamin D exists in two forms, ergocalciferol (vitamin $\mathrm{D}_{2}$ ) and cholecalciferol (vitamin $\left.\mathrm{D}_{3}\right)$; 25-hydroxyergocalciferol $\left(25(\mathrm{OH}) \mathrm{D}_{2}\right)$ and 25 -hydroxycholecalciferol $\left(25(\mathrm{OH}) \mathrm{D}_{3}\right)$ can be quantified separately; and a large study of their relative prevalence in New York has been published ${ }^{(2)}$. However, no cohort studies of mortality have presented associations separately for $25(\mathrm{OH}) \mathrm{D}_{2}$ and $25(\mathrm{OH}) \mathrm{D}_{3}$; many used assays such as RIA and chemiluminescent immunoassays ${ }^{(1)}$ that cannot quantify them separately.

Cholecalciferol is the natural form of vitamin $\mathrm{D}$ in man, endogenously synthesised following UVB irradiation of 7-dehydrocholesterol in skin ${ }^{(3)}$. Dietary sources of cholecalciferol include fatty fish, fortified foods and supplements $^{(3)}$. Ergocalciferol, an exogenous form of vitamin $\mathrm{D}$, is produced in fungi following UVB irradiation 
of ergosterol. People can obtain ergocalciferol from some fortified foods (e.g. margarine $)^{(4)}$ and some species of mushrooms, and it is used in supplements in some countries $^{(3,5)}$. In Australia, margarine contains low levels of ergocalciferol $(1 \mu \mathrm{g} / 100 \mathrm{~g})^{(6)}$.

A systematic review and meta-analysis of randomised controlled trials (RCT) comparing the effects of ergocalciferol and cholecalciferol supplementation on 25(OH)D concentrations found that cholecalciferol is more effective than ergocalciferol at increasing serum $25(\mathrm{OH}) \mathrm{D}^{(4)}$, especially when given as large weekly or monthly doses. Ergocalciferol might also increase catabolism of cholecalciferol; several RCT have reported that ergocalciferol supplementation lowered $25(\mathrm{OH}) \mathrm{D}_{3}$ concentrations $^{(7-13)}$. Reviews of RCT of the effects of vitamin D supplementation on mortality show that there was a modest decrease in mortality for trials of cholecalciferol supplementation, but no decrease for trials of ergocalciferol supplementation, although the ergocalciferol trials were few and of relatively low quality ${ }^{(1,5)}$.

Given limited evidence from trials that ergocalciferol and cholecalciferol supplementation might have different effects on mortality, observational studies of $25(\mathrm{OH}) \mathrm{D}$ and mortality should separate the two forms. The advent of liquid chromatography-tandem mass spectrometry (LC-MS/MS) now makes this possible because it enables simultaneous separate measurement of $25(\mathrm{OH}) \mathrm{D}_{2}$ and $25(\mathrm{OH}) \mathrm{D}_{3}$. We report here analyses of $25(\mathrm{OH}) \mathrm{D}$, $25(\mathrm{OH}) \mathrm{D}_{3}$ and $25(\mathrm{OH}) \mathrm{D}_{2}$ in relation to all-cause mortality in a prospective cohort study of middle-aged men and women. The large size of the study and the availability of data on self-reported health about four years after recruitment also enabled us to assess the potential impact of reverse causality, which has been a major limitation of existing cohort studies.

\section{Methods}

\section{Study design}

A case-cohort study to investigate vitamin D status and risk of cancer, diabetes and mortality was conducted within the Melbourne Collaborative Cohort Study (MCCS), a prospective cohort study of 41514 participants (25\% Southern European migrants) aged predominantly between 40 and 69 years at study recruitment (19901994). Details of the study design, recruitment and procedures are published elsewhere ${ }^{(14)}$.

At baseline participants were interviewed about lifestyle and medical history, completed a self-administered 121-item FFQ developed for the $\operatorname{MCCS}^{(15)}$, and anthropometric measurements (height, weight, waist and hip circumferences) were performed according to a standard protocol. Blood samples were collected and from the second year of recruitment (approximately $75 \%$ of participants), whole blood was spotted on to Guthrie cards that were air dried and stored in the dark at room temperature. About four years after baseline, participants were mailed a questionnaire that included a question about their general health status, rated as poor, fair, good, very good or excellent.

\section{Case-cobort study}

Eligibility for the case-cohort study was restricted to 29206 participants who had dried blood spot samples and, to reduce the possibility of reverse causality, no cancer diagnosed before baseline. The present analysis was restricted to the 2410 people who died by 31 December 2007 and the sub-cohort, a sex-stratified random sample of 2996 participants, with sampling fractions of $7 \cdot 8 \%$ for women and $13.6 \%$ for men, approximately double the number of incident breast cancer and prostate cancer cases, respectively (Fig. 1).

\section{Measurement of 25-bydroxyvitamin D}

The mean time between blood sampling and 25(OH)D measurement was 18.1 (SD 0.8) years. Concentration of $25(\mathrm{OH}) \mathrm{D}_{3}$ has previously been shown to be stable in dried blood spots stored for 8-22 years ${ }^{(16)}$. Measurements of $25(\mathrm{OH}) \mathrm{D}_{2}$ and $25(\mathrm{OH}) \mathrm{D}_{3}$ were made in the laboratory of D.W.E. using LC-MS/MS ${ }^{(16)}$ over 15 months in thirty-one batches of approximately 230 samples each. This laboratory uses National Institute of Standards and Technology calibrants and participates in the Vitamin D External Quality Assessment Scheme. The absolute limits of detection were $1 \mathrm{nmol} / 1$ for $25(\mathrm{OH}) \mathrm{D}_{3}$ and $2 \mathrm{nmol} / 1$ for $25(\mathrm{OH}) \mathrm{D}_{2}{ }^{(16)}$. We have previously reported high reliability of dried blood spot 25(OH)D measurements using 493 replicates from the case-cohort study; within- and between-batch intraclass correlations were 0.82 (95\% CI $0 \cdot 80,0.85)$ and 0.73 (95\% CI $0.68,0.78)$, respectively ${ }^{(17)}$. To estimate the reliability of the $25(\mathrm{OH}) \mathrm{D}_{2}$ measurements, we calculated the intraclass correlation coefficient for the presence $v$. absence of $25(\mathrm{OH}) \mathrm{D}_{2}$ for the 493 replicate measurements. For a binary variable with two replicates, the intraclass correlation is the same as Cohen's $\kappa$. We calculated bias-corrected CI using a bootstrap method with 10000 replications. The intraclass correlation for detectability of $25(\mathrm{OH}) \mathrm{D}_{2}$ was 0.54 (95\% CI $0 \cdot 25,0.72$ ).

Direct comparison between dried blood spot and serum/plasma $25(\mathrm{OH}) \mathrm{D}$ concentrations is problematic because $25(\mathrm{OH}) \mathrm{D}$ is excluded from erythrocytes. Therefore, for initial descriptions of the concentrations, we corrected the observed concentrations for mean sexspecific haematocrit ${ }^{(17)}$. For all other analyses of $25(\mathrm{OH}) \mathrm{D}$ and $25(\mathrm{OH}) \mathrm{D}_{3}$, we used a calibration equation to predict plasma concentration ${ }^{(17)}$. In a subset of sixty-two MCCS participants who had dried blood spot and matching plasma samples (two replicates for each biospecimen type), we found good agreement between dried blood spot 25(OH)D and plasma 25(OH)D concentrations $\left(R^{2}=0.73\right)$ and developed an equation to estimate plasma $25(\mathrm{OH}) \mathrm{D}$ concentration from the dried blood spot 
concentration ${ }^{(17)}$. Because few participants in that study had detectable $25(\mathrm{OH}) \mathrm{D}_{2}$, the calibration equation applies to total $25(\mathrm{OH}) \mathrm{D}$ and $25(\mathrm{OH}) \mathrm{D}_{3}$ only. The sensitivity and specificity of $25(\mathrm{OH}) \mathrm{D}_{2}$ detection in the dried blood spot samples compared with the plasma samples was respectively 100.0 (95\% CI 29.0 100.0) \% and 94.9 (95\% CI 85.9, 98.9) \% for the first replicate, and 50.0 (95\% CI 7.0, 93.0) \% and $100 \cdot 0(95 \% \mathrm{CI} 93 \cdot 8,100 \cdot 0) \%$ for the second replicate.

\section{Ascertainment of deaths}

Deaths to 31 December 2007 were identified by linkage to the Victorian Registry of Births, Deaths and Marriages and the National Death Index at the Australian Institute of Health and Welfare.

\section{Statistical analysis}

Association between 25-hydroxyergocalciferol and 25-hydroxycholecalciferol

One participant whose $25(\mathrm{OH}) \mathrm{D}_{2}$ concentration was several times higher than the next highest value was excluded from these analyses. For participants with detectable $25(\mathrm{OH}) \mathrm{D}_{2}$, we estimated Spearman's correlation between the raw $25(\mathrm{OH}) \mathrm{D}_{3}$ and $25(\mathrm{OH}) \mathrm{D}_{2}$ concentrations. We used linear regression to estimate the difference in mean plasma $25(\mathrm{OH}) \mathrm{D}$ and $25(\mathrm{OH}) \mathrm{D}_{3}$ concentrations for participants with and without detectable $25(\mathrm{OH}) \mathrm{D}_{2}$, with adjustment for sex. For the regression analyses, we used estimated plasma $25(\mathrm{OH}) \mathrm{D}$ and $25(\mathrm{OH}) \mathrm{D}_{3}$ concentrations derived from our calibration equation ${ }^{(17)}$, but did not remove season and batch effects. The adjustment for sex was necessary because men had higher $25(\mathrm{OH}) \mathrm{D}$ and $25(\mathrm{OH}) \mathrm{D}_{3}$ concentrations and were more likely to have detectable $25(\mathrm{OH}) \mathrm{D}_{2}$.

\section{Association between vitamin $D$ and mortality}

Participants with missing data for covariates $(n$ 44) and those with extreme total energy intakes $(<1$ st and $>99$ th sex-specific percentiles; $n$ 100) were excluded (Fig. 1).

Total $25(\mathrm{OH}) \mathrm{D}$ and $25(\mathrm{OH}) \mathrm{D}_{3}$ concentrations were adjusted for batch and season, then converted to plasmaequivalent values using our calibration equation ${ }^{(17)}$. To remove batch effects, we first fitted a mixed-effects linear regression model with a random effect for batch to the sub-cohort observations. Next, for all observations, the predicted batch-specific deviations from the overall mean were subtracted from the observed values. Seasonal variation was removed by fitting linear regression models for $25(\mathrm{OH}) \mathrm{D}$ and $25(\mathrm{OH}) \mathrm{D}_{3}$ as a sinusoidal function of the time of year when blood was sampled ${ }^{(18)}$, then standardising measurements to represent $25(\mathrm{OH}) \mathrm{D}$ and $25(\mathrm{OH}) \mathrm{D}_{3}$ measurements on the dates when the annual mean was attained (15 May and 14 November; late autumn and late spring in Australia). Participants were grouped into sex-specific quintiles based on the distribution of batch- and season-adjusted $25(\mathrm{OH}) \mathrm{D}$ or $25(\mathrm{OH}) \mathrm{D}_{3}$ in the sub-cohort. For $25(\mathrm{OH}) \mathrm{D}_{2}$, batch and seasonal adjustments were not performed because there were too few participants with detectable $25(\mathrm{OH}) \mathrm{D}_{2}$.

Cox regression was used to estimate hazard ratios (HR) and $95 \%$ CI. Barlow's method, robust $\mathrm{SE}^{(19)}$ and Wald tests were used to account for the case-cohort design. Age was the timescale and models were stratified by sex and country of birth. Follow-up began at baseline and ended at the date of death, date left Australia or 31 December 2007, whichever came first. The proportional hazards assumption was assessed by fitting interactions between each covariate separately and attained age. There was no evidence that any covariate violated the assumptions.

We estimated HR for all-cause mortality for each quintile of $25(\mathrm{OH}) \mathrm{D}$ and $25(\mathrm{OH}) \mathrm{D}_{3}$ relative to the lowest quintile and for the presence $v$. absence of detectable $25(\mathrm{OH}) \mathrm{D}_{2}$, adjusting for confounders described below. For $25(\mathrm{OH}) \mathrm{D}$ and $25(\mathrm{OH}) \mathrm{D}_{3}$ we also estimated the HR per $25 \mathrm{nmol} / \mathrm{l}$ by using the continuous forms of the variables. We fitted models with each vitamin $\mathrm{D}$ variable alone, a model including continuous $25(\mathrm{OH}) \mathrm{D}$ and its interaction with detectable $25(\mathrm{OH}) \mathrm{D}_{2}$, and a model including main effects for continuous $25(\mathrm{OH}) \mathrm{D}_{3}$ and detectable $25(\mathrm{OH}) \mathrm{D}_{2}$. The interaction model assesses whether the relationship between $25(\mathrm{OH}) \mathrm{D}$ and mortality depends on the source of the $25(\mathrm{OH}) \mathrm{D}$. Effect modification by sex was assessed by fitting interactions between each vitamin $\mathrm{D}$ variable (continuous for $25(\mathrm{OH}) \mathrm{D}$ and $25(\mathrm{OH}) \mathrm{D}_{3}$ ) and sex.

\section{Confounders}

The following confounders were selected using a causal diagram and a priori knowledge from existing literature: age, sex, country of birth (Australia/New Zealand/Northern Europe or Southern Europe), an area-based measure of socio-economic disadvantage (quintiles from most disadvantaged to least disadvantaged), highest education level attained (primary school, some secondary school, secondary school, tertiary qualification), total energy intake (sex-specific quartiles, $\mathrm{kJ} / \mathrm{d}$ ), Mediterranean diet score (three categories indicating dietary pattern, with the highest representing high adherence to a Mediterranean diet), alcohol (never, former and sex-specific tertiles of current intake), smoking (never, former, current), physical activity (four categories reflecting frequency and intensity of exercise in the past 6 months), waist circumference (sex-specific quartiles, centimetres), and self-reported history of diabetes mellitus, hypertension and CVD (angina, myocardial infarction or stroke).

\section{Sensitivity analyses}

We repeated the analyses for the continuous versions of $25(\mathrm{OH}) \mathrm{D}$ and $25(\mathrm{OH}) \mathrm{D}_{3}$ after excluding participants whose values were greater than the 99th percentiles to assess whether outliers had undue influence on the HR. We also assessed non-linearity of the dose-response relationships by fitting restricted cubic spline models with four knots at fixed, equally spaced percentiles (5\%, 35\%, 65\%, $95 \%)$. 
People in poor health may have had reduced sun exposure, leading to lower $25(\mathrm{OH}) \mathrm{D}_{3}$. They may also have taken supplements, leading to higher $25(\mathrm{OH}) \mathrm{D}_{2}$, since vitamin $\mathrm{D}$ supplements in Australia in the early 1990s contained ergocalciferol $^{(20)}$. Thus, observed associations between vitamin $\mathrm{D}$ and mortality could potentially be explained by reverse causality. To assess this possibility, a sensitivity analysis was conducted by restricting the analysis to people who reported having good, very good or excellent health on the 4-year follow-up questionnaire. For that analysis, followup began on the date of completion of that questionnaire.

Analyses were performed using the statistical software package Stata version $13 \cdot 1$.

\section{Results}

Dried blood spots were not located for sixteen participants and seven deaths were identified after the study began, leaving 5108 for analysis (Fig. 1). All samples had detectable concentrations of $25(\mathrm{OH}) \mathrm{D}_{3}$ (range for haematocritcorrected values, $2 \cdot 4-146.9 \mathrm{nmol} / 1$; to convert $25(\mathrm{OH}) \mathrm{D}$ in $\mathrm{nmol} / \mathrm{l}$ to $\mathrm{ng} / \mathrm{ml}$, divide by $2 \cdot 496)$, whereas $25(\mathrm{OH}) \mathrm{D}_{2}$ was detected in sixty-three samples (1.2\%; range for haematocrit-corrected values, $4 \cdot 1-195.0 \mathrm{nmol} / \mathrm{l})$. The median plasma-equivalent $25(\mathrm{OH}) \mathrm{D}$ concentration, adjusted for batch and season, was $48.4 \mathrm{nmol} / \mathrm{l}$; $99 \%$ of values were greater than $19.7 \mathrm{nmol} / 1$ and $1 \%$ greater than $107 \cdot 3 \mathrm{nmol} / \mathrm{l}$.

Participants who were born in Southern Europe, had primary school education or less, were in the lowest energy intake quartile, did not consume alcohol (both lifetime abstainers and former drinkers), were current smokers, did not do any physical activity, were in the largest waist circumference quartile or had diabetes mellitus at baseline were more likely to have low $25(\mathrm{OH}) \mathrm{D}_{3}$ concentrations (Table 1). These patterns were almost identical for 25(OH)D (data not shown). Participants with high alcohol consumption and current smokers were less likely to have $25(\mathrm{OH}) \mathrm{D}_{2}$, while those who took multivitamins were more likely to have $25(\mathrm{OH}) \mathrm{D}_{2}$ (Table 2 ).

The mean plasma $25(\mathrm{OH}) \mathrm{D}$ concentration was 11.9 (95\% CI 7.3, 16.6) nmol/1 higher $(P<0.001)$ when $25(\mathrm{OH}) \mathrm{D}_{2}$ was detected than when it was not detected, whereas the mean plasma $25(\mathrm{OH}) \mathrm{D}_{3}$ concentration was 4.9 (95\% CI $-9.6,-0.3) \mathrm{nmol} / \mathrm{l}$ lower $(P=0.04)$. For participants with detectable $25(\mathrm{OH}) \mathrm{D}_{2}$ there was a weak, non-significant inverse correlation between their raw $25(\mathrm{OH}) \mathrm{D}_{2}$ and $25(\mathrm{OH}) \mathrm{D}_{3}$ concentrations (Spearman's correlation $=-0.09, P=0.50)$.

\section{Vitamin $D$ and mortality}

During a mean of 13.7 (SD 2.2) years of follow-up (maximum 16.9 years), 2410 (8.3\%) participants died. The present analysis included 4964 participants, 2307 of whom died (Fig. 1).
The HR for the highest compared with the lowest total $25(\mathrm{OH}) \mathrm{D}$ quintile was $0.67(95 \% \mathrm{CI} 0.54,0.84)$ and the HR per $25 \mathrm{nmol} / 1$ increment in $25(\mathrm{OH}) \mathrm{D}$ was $0.86(95 \% \mathrm{CI}$ $0.78,0.96 ; P=0.007$; Table 3$)$. There was no evidence that the splines fitted better than a linear trend $(P=0.44)$ and the HR was unchanged after excluding outliers (data not shown).

Because few participants had $25(\mathrm{OH}) \mathrm{D}_{2}$, the $\mathrm{HR}$ for $25(\mathrm{OH}) \mathrm{D}_{3}$ were essentially identical to those for total 25(OH)D (Table 3). The splines fitted no better than a linear trend $(P=0.42)$ and excluding outliers did not affect the HR (data not shown). The HR for the presence of detectable $25(\mathrm{OH}) \mathrm{D}_{2}$ was 1.80 (95\% CI 1.09, 2.97; $P=0.02$; Table 3 ). One batch of measurements had a disproportionate number of samples with $25(\mathrm{OH}) \mathrm{D}_{2}$; results were similar when this batch was excluded ( $\mathrm{HR}=1 \cdot 88 ; 95 \% \mathrm{CI} 1 \cdot 07,3 \cdot 28 ; P=0 \cdot 03)$.

When $25(\mathrm{OH}) \mathrm{D}_{3}$ and detectable $25(\mathrm{OH}) \mathrm{D}_{2}$ were included in the same model, their HR changed little (Table 3). The interaction between the continuous $25(\mathrm{OH}) \mathrm{D}$ and $25(\mathrm{OH}) \mathrm{D}_{2}$ was significant $(P=0 \cdot 02)$. From this model, the HR per $25 \mathrm{nmol} / 1$ increment in $25(\mathrm{OH}) \mathrm{D}$ concentration was 0.85 (95\% CI $0.77,0.95)$ when there was no detectable $25(\mathrm{OH}) \mathrm{D}_{2}$ and 1.06 (95\% CI 0.87, 1.29) when there was detectable $25(\mathrm{OH}) \mathrm{D}_{2}$.

There was little evidence that the HR for any of the vitamin $\mathrm{D}$ variables varied by sex (interactions: $25(\mathrm{OH}) \mathrm{D}$, $\left.P=0 \cdot 30 ; 25(\mathrm{OH}) \mathrm{D}_{3}, P=0 \cdot 28 ; 25(\mathrm{OH}) \mathrm{D}_{2}, P=0 \cdot 25\right)$.

\section{Vitamin $D$ and mortality in people reporting good bealth}

When restricted to the 3159 participants (1136 of whom died) who reported good, very good or excellent health four years after baseline blood sample collection, forty-six had detectable $25(\mathrm{OH}) \mathrm{D}_{2}$. The $\mathrm{HR}$ per $25 \mathrm{nmol} / 1$ increment in $25(\mathrm{OH}) \mathrm{D}$ and $25(\mathrm{OH}) \mathrm{D}_{3}$ were $0.85(95 \% \mathrm{CI} 0.73$, $0.98 ; P=0.021)$ and 0.83 (95\% CI 0.72, 0.95; $P=0.009$ ), respectively. The HR for detectable $25(\mathrm{OH}) \mathrm{D}_{2}$ was 1.75 (95\% CI $0.98,3.10 ; P=0.06$ ). The HR from the model including $25(\mathrm{OH}) \mathrm{D}$ and the interaction with detectable $25(\mathrm{OH}) \mathrm{D}_{2}$ were also similar to those for all participants (data not shown).

\section{Discussion}

Higher $25(\mathrm{OH}) \mathrm{D}_{3}$ and $25(\mathrm{OH}) \mathrm{D}$ concentrations were associated with a moderately reduced risk of death, whereas the presence of $25(\mathrm{OH}) \mathrm{D}_{2}$ was associated with a moderately increased risk of death, despite participants with detectable $25(\mathrm{OH}) \mathrm{D}_{2}$ having higher mean $25(\mathrm{OH}) \mathrm{D}$ concentration. The inverse association between mortality and $25(\mathrm{OH}) \mathrm{D}$ was restricted to those with no detectable $25(\mathrm{OH}) \mathrm{D}_{2}$. The $\mathrm{HR}$ for $25(\mathrm{OH}) \mathrm{D}_{3}$ and detectable $25(\mathrm{OH}) \mathrm{D}_{2}$ changed little when they were included in the same model. These associations were similar when the 


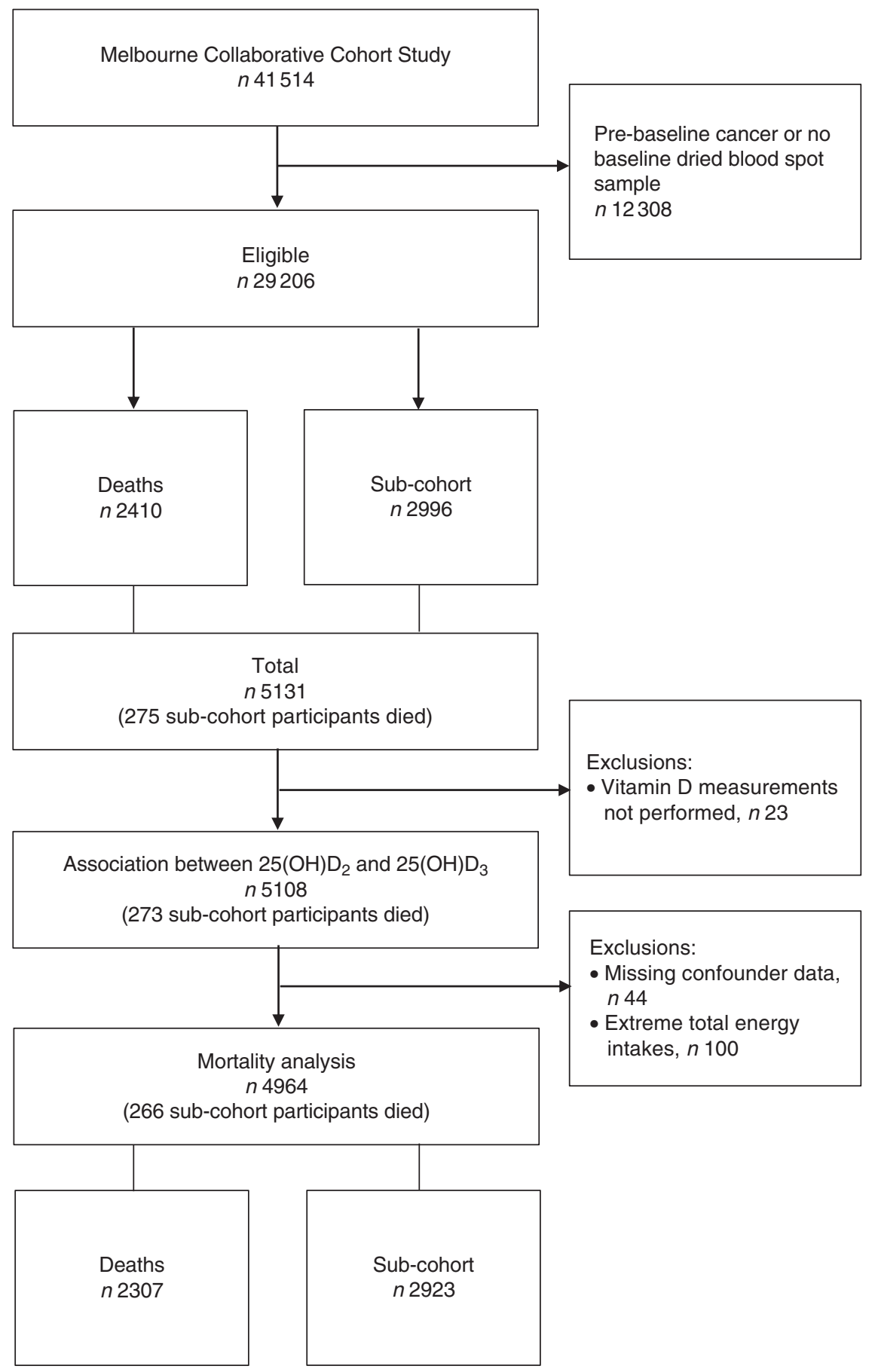

Fig. 1 Flow of participants in the present study. The sub-cohort was a sex-stratified random sample of eligible participants. Deaths were all deaths between baseline (1990-1994) and 31 December $2007\left(25(\mathrm{OH}) \mathrm{D}_{2}, 25\right.$-hydroxyergocalciferol; 25(OH) $\mathrm{D}_{3}$, 25-hydroxycholecalciferol)

analysis was restricted to people who reported being in good to excellent health about four years after blood draw.

Strengths of the current study include its prospective design, long follow-up, use of highly sensitive LC-MS/MS for separate measurement of both 25(OH)D forms, availability of extensive information on potential confounders, accurate and complete mortality data, and broad generalisability. Measurement error is unlikely to explain the associations: the samples were analysed in random order and blind to outcome status and so any measurement error would be non-differential and attenuate associations. We had no data on vitamin D supplementation, but only $16 \%$ of participants reported using multivitamins at baseline (which at the time in Australia contained ergocalciferol only, but which now contain cholecalciferol only). We controlled for history of disease 
Table 1 Baseline characteristics of sub-cohort participants included in the mortality analyses $(n$ 2923) according to quintiles of batchand season-adjusted plasma 25-hydroxycholecalciferol $\left(25(\mathrm{OH}) \mathrm{D}_{3}\right)$ concentrations (plasma concentration estimated from calibration equation $^{(17)}$ ); Melbourne Collaborative Cohort Study

\begin{tabular}{|c|c|c|c|c|c|c|c|c|c|c|}
\hline & \multicolumn{10}{|c|}{$25(\mathrm{OH}) \mathrm{D}_{3}$ quintile $(\mathrm{nmol} / /)^{*}$} \\
\hline & \multicolumn{2}{|c|}{ Quintile 1} & \multicolumn{2}{|c|}{ Quintile 2} & \multicolumn{2}{|c|}{ Quintile 3} & \multicolumn{2}{|c|}{ Quintile 4} & \multicolumn{2}{|c|}{ Quintile 5} \\
\hline & \multicolumn{2}{|c|}{$(n 583 ; 20.0 \%)$} & \multicolumn{2}{|c|}{$(n 585 ; 20.0 \%)$} & \multicolumn{2}{|c|}{$(n 585 ; 20.0 \%)$} & \multicolumn{2}{|c|}{$(n 585 ; 20.0 \%)$} & \multicolumn{2}{|c|}{$(n 585 ; 20.0 \%)$} \\
\hline & $\begin{array}{l}\text { Median } \\
\text { or } n\end{array}$ & $\begin{array}{c}\text { IQR or } \\
\%\end{array}$ & $\begin{array}{l}\text { Median } \\
\text { or } n\end{array}$ & $\begin{array}{c}\text { IQR or } \\
\%\end{array}$ & $\begin{array}{l}\text { Median } \\
\text { or } n\end{array}$ & $\begin{array}{c}\text { IQR or } \\
\%\end{array}$ & $\begin{array}{l}\text { Median } \\
\text { or } n\end{array}$ & $\begin{array}{c}\text { IQR or } \\
\%\end{array}$ & $\begin{array}{l}\text { Median } \\
\quad \text { or } n\end{array}$ & $\begin{array}{c}\text { IQR or } \\
\%\end{array}$ \\
\hline \multicolumn{11}{|l|}{ Plasma $25(\mathrm{OH}) \mathrm{D}_{3}(\mathrm{nmol} / \mathrm{I})$, median and IQR } \\
\hline Overall & $30 \cdot 2$ & $6 \cdot 3$ & $41 \cdot 3$ & $8 \cdot 7$ & $51 \cdot 2$ & $11 \cdot 8$ & $60 \cdot 8$ & $14 \cdot 8$ & $75 \cdot 2$ & $21 \cdot 3$ \\
\hline Females & 29.1 & 4.9 & $36 \cdot 5$ & 3.4 & $42 \cdot 9$ & 3.4 & $50 \cdot 6$ & 4.5 & $62 \cdot 7$ & $10 \cdot 3$ \\
\hline Males & $32 \cdot 2$ & 8.8 & $45 \cdot 2$ & $5 \cdot 2$ & 54.7 & 4.6 & 65.3 & 6.4 & $82 \cdot 8$ & $14 \cdot 7$ \\
\hline Male sex & 322 & $20 \cdot 0$ & 323 & $20 \cdot 0$ & 323 & $20 \cdot 0$ & 323 & $20 \cdot 0$ & 323 & $20 \cdot 0$ \\
\hline \multicolumn{11}{|l|}{ Number of deaths } \\
\hline Females & 17 & $21 \cdot 3$ & 24 & $30 \cdot 0$ & 11 & $13 \cdot 8$ & 12 & $15 \cdot 0$ & 16 & $20 \cdot 0$ \\
\hline Males & 45 & $24 \cdot 2$ & 37 & $19 \cdot 9$ & 40 & 21.5 & 33 & $17 \cdot 7$ & 31 & $16 \cdot 7$ \\
\hline Age (years), median and IQR & $53 \cdot 8$ & $15 \cdot 3$ & $54 \cdot 3$ & 14.8 & $53 \cdot 2$ & $14 \cdot 8$ & 53.6 & $15 \cdot 3$ & $54 \cdot 1$ & $15 \cdot 9$ \\
\hline \multicolumn{11}{|l|}{ Country of birth } \\
\hline Australia/NZ/Northern Europe & 409 & $16 \cdot 7$ & 443 & $18 \cdot 1$ & 495 & $20 \cdot 3$ & 541 & $22 \cdot 1$ & 555 & $22 \cdot 7$ \\
\hline Southern Europe & 174 & $36 \cdot 3$ & 142 & 29.6 & 90 & $18 \cdot 8$ & 44 & $9 \cdot 2$ & 30 & $6 \cdot 3$ \\
\hline Socio-economic disadvantage & & & & & & & & & & \\
\hline 1st quintile (most disadvantage) & 81 & $21 \cdot 2$ & 69 & $18 \cdot 0$ & 76 & $19 \cdot 8$ & 84 & $21 \cdot 9$ & 73 & $19 \cdot 1$ \\
\hline 2nd quintile & 101 & $21 \cdot 1$ & 104 & $21 \cdot 8$ & 91 & $19 \cdot 0$ & 98 & 20.5 & 84 & 17.6 \\
\hline 3rd quintile & 87 & $18 \cdot 0$ & 97 & $20 \cdot 1$ & 101 & $20 \cdot 9$ & 98 & $20 \cdot 3$ & 100 & $20 \cdot 7$ \\
\hline 4th quintile & 135 & $20 \cdot 0$ & 131 & $19 \cdot 4$ & 135 & $20 \cdot 0$ & 141 & $20 \cdot 9$ & 134 & $19 \cdot 8$ \\
\hline 5th quintile (least disadvantage) & 179 & $19 \cdot 8$ & 184 & 20.4 & 182 & $20 \cdot 2$ & 164 & 18.2 & 194 & 21.5 \\
\hline Education & & & & & & & & & & \\
\hline Primary school or less & 95 & 28.7 & 102 & $30 \cdot 8$ & 55 & $16 \cdot 6$ & 45 & 13.6 & 34 & $10 \cdot 3$ \\
\hline Some secondary school & 189 & $17 \cdot 2$ & 203 & 18.5 & 222 & $20 \cdot 2$ & 233 & 21.2 & 253 & 23.0 \\
\hline Secondary school & 138 & $19 \cdot 9$ & 112 & $16 \cdot 2$ & 156 & $22 \cdot 5$ & 138 & $19 \cdot 9$ & 149 & $21 \cdot 5$ \\
\hline Tertiary & 161 & $20 \cdot 2$ & 168 & $21 \cdot 0$ & 152 & $19 \cdot 0$ & 169 & $21 \cdot 2$ & 149 & $18 \cdot 7$ \\
\hline Energy intake $(\mathrm{kJ} / \mathrm{d}$, sex-specific quartiles) $\dagger$ & & & & & & & & & & \\
\hline 1 & 174 & $23 \cdot 8$ & 164 & $22 \cdot 5$ & 138 & $18 \cdot 9$ & 130 & $17 \cdot 8$ & 124 & $17 \cdot 0$ \\
\hline 2 & 144 & $19 \cdot 7$ & 137 & $18 \cdot 7$ & 147 & $20 \cdot 1$ & 147 & $20 \cdot 1$ & 156 & $21 \cdot 3$ \\
\hline 3 & 144 & $19 \cdot 7$ & 127 & 17.4 & 152 & $20 \cdot 8$ & 151 & $20 \cdot 6$ & 158 & $21 \cdot 6$ \\
\hline 4 & 121 & $16 \cdot 6$ & 157 & 21.5 & 148 & $20 \cdot 3$ & 157 & 21.5 & 147 & $20 \cdot 1$ \\
\hline Mediterranean diet score & & & & & & & & & & \\
\hline 1 (low) & 147 & $20 \cdot 6$ & 139 & 19.4 & 154 & 21.5 & 131 & $18 \cdot 3$ & 144 & $20 \cdot 1$ \\
\hline 2 (medium) & 370 & $20 \cdot 2$ & 355 & $19 \cdot 4$ & 358 & $19 \cdot 6$ & 380 & $20 \cdot 8$ & 367 & $20 \cdot 1$ \\
\hline 3 (high) & 66 & 17.5 & 91 & $24 \cdot 1$ & 73 & $19 \cdot 3$ & 74 & $19 \cdot 6$ & 74 & $19 \cdot 6$ \\
\hline Alcohol intake $(\mathrm{g} / \mathrm{d}) \ddagger$ & & & & & & & & & & \\
\hline Never & 152 & $23 \cdot 2$ & 140 & $21 \cdot 3$ & 131 & $20 \cdot 0$ & 119 & $18 \cdot 1$ & 114 & $17 \cdot 4$ \\
\hline Former & 35 & $27 \cdot 3$ & 26 & $20 \cdot 3$ & 25 & 19.5 & 20 & $15 \cdot 6$ & 22 & $17 \cdot 2$ \\
\hline Low & 127 & 18.5 & 142 & $20 \cdot 7$ & 141 & 20.5 & 128 & $18 \cdot 6$ & 149 & $21 \cdot 7$ \\
\hline Medium & 135 & $19 \cdot 3$ & 118 & $16 \cdot 9$ & 148 & $21 \cdot 2$ & 151 & $21 \cdot 6$ & 147 & $21 \cdot 0$ \\
\hline High & 134 & $17 \cdot 8$ & 159 & $21 \cdot 1$ & 140 & $18 \cdot 6$ & 167 & $22 \cdot 2$ & 153 & $20 \cdot 3$ \\
\hline Smoking status & & & & & & & & & & \\
\hline Never & 313 & $19 \cdot 8$ & 321 & $20 \cdot 3$ & 302 & $19 \cdot 1$ & 327 & $20 \cdot 7$ & 320 & $20 \cdot 2$ \\
\hline Former & 190 & $18 \cdot 7$ & 196 & $19 \cdot 3$ & 214 & $21 \cdot 0$ & 200 & 19.7 & 217 & 21.3 \\
\hline Current & 80 & $24 \cdot 8$ & 68 & $21 \cdot 1$ & 69 & 21.4 & 58 & $18 \cdot 0$ & 48 & 14.9 \\
\hline Physical activity score & & & & & & & & & & \\
\hline None & 158 & $26 \cdot 5$ & 133 & $22 \cdot 3$ & 110 & 18.5 & 103 & $17 \cdot 3$ & 92 & $15 \cdot 4$ \\
\hline Low & 124 & $21 \cdot 7$ & 126 & $22 \cdot 1$ & 115 & $20 \cdot 1$ & 105 & $18 \cdot 4$ & 101 & $17 \cdot 7$ \\
\hline Medium & 199 & $19 \cdot 9$ & 201 & $20 \cdot 1$ & 209 & $20 \cdot 9$ & 189 & 18.9 & 200 & $20 \cdot 0$ \\
\hline High & 102 & 13.5 & 125 & $16 \cdot 5$ & 151 & $19 \cdot 9$ & 188 & 24.8 & 192 & $25 \cdot 3$ \\
\hline Waist circumference (cm, sex-specific quartiles) $\ddagger, \S$ & & & & & & & & & & \\
\hline 1 & 127 & $17 \cdot 7$ & 147 & 20.5 & 126 & 17.6 & 149 & $20 \cdot 8$ & 169 & 23.5 \\
\hline 2 & 124 & $16 \cdot 9$ & 135 & 18.4 & 153 & $20 \cdot 9$ & 157 & 21.4 & 164 & $22 \cdot 4$ \\
\hline 3 & 142 & $19 \cdot 1$ & 151 & $20 \cdot 4$ & 168 & $22 \cdot 6$ & 153 & $20 \cdot 6$ & 128 & $17 \cdot 3$ \\
\hline 4 & 190 & $26 \cdot 0$ & 152 & $20 \cdot 8$ & 138 & $18 \cdot 9$ & 126 & $17 \cdot 3$ & 124 & $17 \cdot 0$ \\
\hline History of diabetes mellitus & 28 & $35 \cdot 9$ & 15 & 19.2 & 16 & 20.5 & 12 & $15 \cdot 4$ & 7 & 9.0 \\
\hline History of hypertension & 101 & $19 \cdot 0$ & 113 & $21 \cdot 2$ & 107 & $20 \cdot 1$ & 93 & 17.5 & 118 & $22 \cdot 2$ \\
\hline History of CVD (angina, myocardial infarction or stroke) & 35 & $19 \cdot 0$ & 43 & 23.4 & 35 & $19 \cdot 0$ & 27 & 14.7 & 44 & 23.9 \\
\hline
\end{tabular}

IQR, interquartile range; NZ, New Zealand.

Values are median and interquartile range for $25(\mathrm{OH}) \mathrm{D}_{3}$ concentrations and age, or number and percentage for categorical variables.

${ }^{*}$ To convert $25(\mathrm{OH}) \mathrm{D}$ in $\mathrm{nmol} / \mathrm{l}$ to $\mathrm{ng} / \mathrm{ml}$, divide by 2.496 .

†Quartiles of total energy intake $(\mathrm{kJ} / \mathrm{d}): 1$, females $=3149-6301$, males $=3755-7399 ; 2$, females $=6302-8007$, males $=7400-9192 ; 3$, females $=8008-9827$, males $=9193-11397 ; 4$, females $=9828-18831$, males $=11398-22150$.

$\ddagger$ Categories of alcohol intake $(\mathrm{g} / \mathrm{d})$ : low, females 0.1-4.2, males 0.1-9.2; medium, females 4.3-14.9, males 9.3-25.7; high, females 15.0-117.6, males 25.8-221.4. $\S$ Quartiles of waist circumference $(\mathrm{cm}): 1$, females $=52 \cdot 7-70 \cdot 6$, males $=62 \cdot 0-85 \cdot 9 ; 2$, females $=70 \cdot 7-76 \cdot 9$, males $=86 \cdot 0-91 \cdot 9 ; 3$, females $=77 \cdot 0-85 \cdot 9$, males $=$ 92.0-98.4; 4, females $=86 \cdot 0-134 \cdot 9$, males $=98 \cdot 5-131 \cdot 0$. 
Table 2 Presence of 25-hydroxyergocalciferol $\left(25(\mathrm{OH}) \mathrm{D}_{2}\right)$ according to baseline characteristics of study participants; Melbourne Collaborative Cohort Study

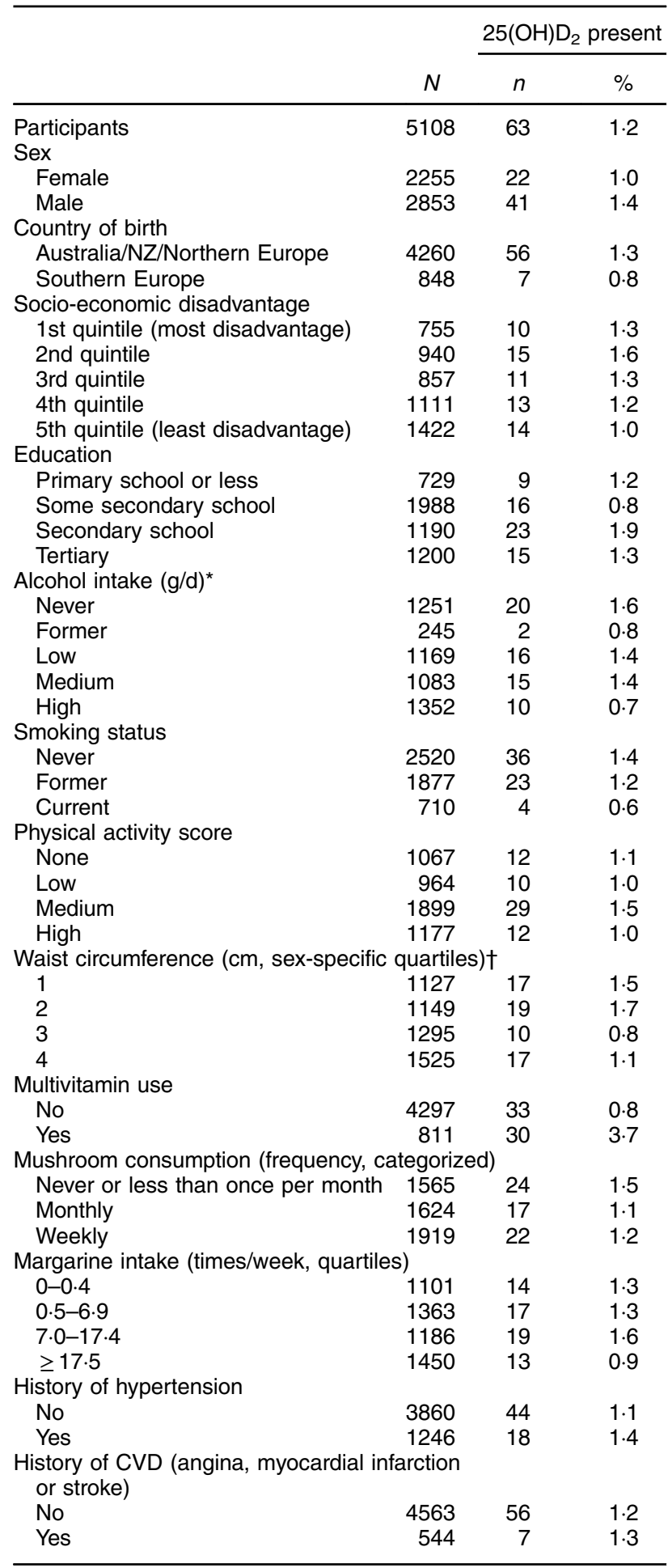

NZ, New Zealand.

All values are number and percentage

${ }^{*}$ Categories of alcohol intake $(\mathrm{g} / \mathrm{d})$ : low, females $=0 \cdot 1-4 \cdot 2$, males $=0 \cdot 1-9 \cdot 2$; medium, females $=4 \cdot 3-14 \cdot 9$, males $=9 \cdot 3-25 \cdot 7$; high, females $=15 \cdot 0-157 \cdot 9$ males $=25 \cdot 8-232 \cdot 2$.

tQuartiles of waist circumference $(\mathrm{cm}): 1$, females $=47.0-70.5$, males $=62 \cdot 0-85 \cdot 9 ; 2$, females $=70 \cdot 6-76 \cdot 9$, males $=86 \cdot 0-91 \cdot 9 ; 3$, females $=$ $77 \cdot 0-85.4$, males $=92 \cdot 0-98 \cdot 3 ; \quad 4$, females $=85 \cdot 5-153 \cdot 6, \quad$ males $=$ 98.4-143.0. and several risk factors, but cannot rule out the possibility of residual confounding. Given the small number of people with detectable $25(\mathrm{OH}) \mathrm{D}_{2}$, chance is also a potential explanation for its positive association with mortality.

Inclusion of middle-aged adults with no pre-baseline cancer reduced the possibility of reverse causality explaining the results. However, reverse causality might explain the positive association with $25(\mathrm{OH}) \mathrm{D}_{2}$ and inverse association with $25(\mathrm{OH}) \mathrm{D}_{3}$ if people in poor health were more likely to take supplements and spend less time outdoors, thus having lower concentrations of $25(\mathrm{OH}) \mathrm{D}_{3}$. Our sensitivity analysis, restricted to participants in good to excellent health several years after baseline, was designed to assess this possibility. While it is not possible to rule out reverse causality, the sensitivity analysis showed no evidence of its occurrence. The $\mathrm{HR}$ for total $25(\mathrm{OH}) \mathrm{D}$ and $25(\mathrm{OH}) \mathrm{D}_{3}$ were very similar; this might not be the case in populations with more ergocalciferol use, such as in the USA ${ }^{(2)}$. Finally, the absolute $25(\mathrm{OH}) \mathrm{D}$ values reported should be interpreted cautiously as these were plasma-equivalent $25(\mathrm{OH}) \mathrm{D}$ concentrations estimated from measurements of $25(\mathrm{OH}) \mathrm{D}$ in dried blood spots and with adjustment for batch and season.

A recent meta-analysis of cohort studies of vitamin D and all-cause mortality found a relative risk (RR) of 1.16 (95\% CI $1.08,1.23)$ for a $10 \mathrm{ng} / \mathrm{ml}$ decrease in $25(\mathrm{OH}) \mathrm{D}$, which is equivalent to 0.86 (95\% CI $0.81,0.93)$ for a $25 \mathrm{nmol} / \mathrm{l}$ increase, and thus identical to the estimate from our study for $25(\mathrm{OH}) \mathrm{D}^{(1)}$. There was substantial heterogeneity between studies $\left(I^{2}=90 \%\right)$ that did not appear to be explained by any of the study characteristics used to form subgroups (no formal meta-regression was performed). The association was similar when stratified by latitude $\left(\leq 40^{\circ} v \cdot>40^{\circ}\right)$ and by age at baseline $(<70 v . \geq 70$ years $)^{(1)}$. It was slightly stronger for males, whereas we found similar associations for men and women. The association was stronger in the first five years after baseline ${ }^{(1)}$. One possible explanation for this finding is reverse causality - our study is one of few that have been able to assess this possibility by performing an analysis restricted to people in good health several years after baseline. Our results for $25(\mathrm{OH}) \mathrm{D}$ are also consistent with a recent metaanalysis of individual data from eight cohort studies from Europe and the USA, in which the RR for mortality in the lowest $v$. the highest quintile was 1.57 (95\% CI 1.36, 1.81), which is equivalent to RR of $0.64(=1 / 1.57)$ for the highest $v$. the lowest quintile (our corresponding HR was 0.67) ${ }^{(21)}$. In that study, there was also little heterogeneity by age and $\operatorname{sex}^{(21)}$. Some cohort studies have found U-shaped or reverse J-shaped relationships between 25(OH)D and all-cause mortality ${ }^{(22-25)}$ but we found no such evidence. However, because few of our participants had concentrations above $100 \mathrm{nmol} / \mathrm{l}$, our ability to assess curvilinear relationships was limited. 
Table 3 Hazard ratios $(\mathrm{HR})$ and $95 \% \mathrm{Cl}$ for all-cause mortality for total 25-hydroxyvitamin D (25(OH)D), 25-hydroxycholecalciferol $\left(25(\mathrm{OH}) \mathrm{D}_{3}\right)$ and 25-hydroxyergocalciferol $\left(25(\mathrm{OH}) \mathrm{D}_{2}\right)$; Melbourne Collaborative Cohort Study

\begin{tabular}{|c|c|c|c|c|c|c|c|c|c|c|c|}
\hline & \multicolumn{2}{|c|}{ Concentration $(\mathrm{nmol} / \mathrm{l})^{*}$} & \multirow[b]{2}{*}{$n$} & \multirow[b]{2}{*}{ Deaths } & \multirow[b]{2}{*}{ Person-years† } & \multicolumn{3}{|c|}{ Single-variable model } & \multicolumn{3}{|c|}{ Two-variable model } \\
\hline & Median & IQR & & & & $\mathrm{HR} \ddagger$ & $95 \% \mathrm{Cl}$ & $P_{\text {trend }}$ & HR $\ddagger$ & $95 \% \mathrm{Cl}$ & $P_{\text {trend }}$ \\
\hline \multicolumn{12}{|l|}{ Total plasma $25(\mathrm{OH}) \mathrm{D} \S$} \\
\hline \multicolumn{12}{|l|}{ Quintile } \\
\hline Q1 & $30 \cdot 3$ & $7 \cdot 6$ & 1067 & 545 & 7885 & 1.00 & ref. & 0.001 & & & \\
\hline Q2 & 41.3 & 8.9 & 1008 & 485 & 7977 & 0.85 & $0.68,1.06$ & & & & \\
\hline Q3 & 51.6 & 11.8 & 992 & 458 & 8020 & 0.90 & $0.72,1.11$ & & & & \\
\hline Q4 & $61 \cdot 0$ & 14.9 & 958 & 417 & 8056 & 0.80 & $0.64,1.00$ & & & & \\
\hline Q5 & $77 \cdot 0$ & $21 \cdot 1$ & 939 & 402 & 8150 & 0.67 & $0.54,0.84$ & & & & \\
\hline Per $25 \mathrm{nmol} / \mathrm{l}$ increase & & & 4964 & 2307 & 40088 & 0.86 & $0.78,0.96$ & 0.007 & & & \\
\hline $25(\mathrm{OH}) \mathrm{D}_{2}$ absent & & & & & & & & & $0.85 \|$ & $0.77,0.95$ & 0.003 \\
\hline $25(\mathrm{OH}) \mathrm{D}_{2}$ present & & & & & & & & & $1.06 \|$ & $0.87,1.29$ & 0.55 \\
\hline \multicolumn{12}{|l|}{ Plasma $25(\mathrm{OH}) \mathrm{D}_{3} \ddagger$} \\
\hline \multicolumn{12}{|l|}{ Quintile } \\
\hline Q1 & $30 \cdot 1$ & $7 \cdot 3$ & 1066 & 545 & 7884 & 1.00 & ref. & 0.001 & & & \\
\hline Q2 & 41.0 & 8.7 & 1011 & 487 & 7988 & 0.86 & $0.69,1.08$ & & & & \\
\hline Q3 & 51.4 & 11.6 & 991 & 457 & 8003 & 0.88 & $0.71,1.10$ & & & & \\
\hline Q4 & $60 \cdot 7$ & $14 \cdot 3$ & 953 & 413 & 8050 & 0.77 & $0.62,0.97$ & & & & \\
\hline Q5 & $76 \cdot 2$ & 20.9 & 943 & 405 & 8163 & 0.68 & $0.54,0.85$ & & & & \\
\hline Per $25 \mathrm{nmol} / / \mathrm{l}$ increase & & & 4964 & 2307 & 40088 & 0.85 & $0.77,0.95$ & 0.003 & 0.86 | & $0.77,0.95$ & 0.004 \\
\hline \multicolumn{12}{|l|}{ Plasma $25(\mathrm{OH}) \mathrm{D}_{2}$} \\
\hline Absent & 0.0 & 0.0 & 4902 & 2273 & 39653 & 1.00 & ref. & & & & \\
\hline Present & 13.7 & $9 \cdot 2$ & 62 & 34 & 436 & 1.80 & $1.09,2.97$ & 0.023 & $1.73 \pi$ & $1.05,2.87$ & 0.032 \\
\hline
\end{tabular}

IQR, interquartile range; ref., reference category.

${ }^{*}$ To convert $25(\mathrm{OH}) \mathrm{D}$ in $\mathrm{nmol} / \mathrm{l}$ to $\mathrm{ng} / \mathrm{ml}$, divide by 2.496 .

†Sub-cohort participants.

$\ddagger$ Adjusted for age, area-based index of socio-economic disadvantage, education, total energy intake, Mediterranean diet pattern, alcohol intake, smoking status, physical activity, waist measurement, diabetes mellitus at baseline, history of hypertension, history of angina, history of myocardial infarction, history of stroke, and stratified by sex and Southern European migrant status.

§Adjusted for batch and seasonal effects.

IIInteraction between $25(\mathrm{OH}) \mathrm{D}$ and $25(\mathrm{OH}) \mathrm{D}_{2}$

ףMutual adjustment for $25(\mathrm{OH}) \mathrm{D}_{2}$ and $25(\mathrm{OH}) \mathrm{D}_{3}$.

We are not aware of any cohort studies of $25(\mathrm{OH}) \mathrm{D}_{2}$ and $25(\mathrm{OH}) \mathrm{D}_{3}$ and mortality. According to a Cochrane review of RCT of vitamin D supplementation, cholecalciferol reduced all-cause mortality by $6 \%(\mathrm{RR}=0.94 ; 95 \% \mathrm{CI}$ $0.91,0.98 ; P=0.002)$. Ergocalciferol had no apparent beneficial effect (RR $=1.02 ; 95 \% \mathrm{CI} 0.96,1.08 ; P=0.54)$, but in RCT involving participants with vitamin D insufficiency, the risk of mortality was elevated $(\mathrm{RR}=1 \cdot 20 ; 95 \%$ CI 1.05, 1.37; $P=0.008)^{(5)}$. The authors commented that the effect of vitamin $\mathrm{D}_{2}$ may be neutral or even detrimental ${ }^{(5)}$. In another meta-analysis of RCT, cholecalciferol supplementation reduced all-cause mortality $(\mathrm{RR}=0.89$; $95 \%$ CI $0.80,0.99)$. Overall, ergocalciferol had no beneficial effect $(\mathrm{RR}=1.04 ; 95 \% \mathrm{CI} 0.97,1 \cdot 11)$, but increased mortality risk in RCT using doses of $15-50 \mu \mathrm{g} / \mathrm{d}(600-$ $2000 \mathrm{IU} / \mathrm{d} ; \mathrm{RR}=1 \cdot 20 ; 95 \%$ CI $1.05,1.38)$, in RCT with shorter mean intervention periods $(<1.5$ years; $R R=1.20$; $95 \%$ CI $1.05,1.37)$ and in RCT with shorter follow-up $(<2 \cdot 5 \text { years; } \mathrm{RR}=1 \cdot 19 ; 95 \% \mathrm{CI} 1 \cdot 04,1 \cdot 36)^{(1)}$. The median follow-up from the included RCT was only 1.4 years, the median age of participants was 77 years, there were relatively few deaths in each study, and thirteen out of the twenty-two RCT involved participants with pre-existing chronic disease ${ }^{(1)}$. Thus, existing RCT are not necessarily generalisable to younger/middle-aged community-dwelling populations.
Our findings that participants with detectable $25(\mathrm{OH}) \mathrm{D}_{2}$ had higher mean $25(\mathrm{OH}) \mathrm{D}$ but lower mean $25(\mathrm{OH}) \mathrm{D}_{3}$ concentration is consistent with the Osteoporotic Fractures in Men Study $(\mathrm{MrOS})^{(26)}$. These findings complement evidence from RCT showing that ergocalciferol might interfere with production of $25(\mathrm{OH}) \mathrm{D}_{3}$ and/or induce processes that degrade $25(\mathrm{OH}) \mathrm{D}_{3}{ }^{(7-13)}$.

Several potential mechanisms could explain differences in effects of ergocalciferol and cholecalciferol. The presence of a methyl group on C24 of ergocalciferol metabolites may slightly alter their ability to bind to, or their affinity for, vitamin $\mathrm{D}$ binding protein ${ }^{(27)}$, vitamin $\mathrm{D}$ hydroxylases and the vitamin $\mathrm{D}$ receptor ${ }^{(28)}$. The lower affinity of $25(\mathrm{OH}) \mathrm{D}_{2}$ for vitamin $\mathrm{D}$ binding protein relative to $25(\mathrm{OH}) \mathrm{D}_{3}$ means its free fraction in blood is likely to be higher, consistent with the faster turnover of $25(\mathrm{OH})$ $\mathrm{D}_{2}{ }^{(8,27)}$. The shorter circulating half-life of ergocalciferol metabolites may lead to up-regulation of enzymes that not only metabolise ergocalciferol, but also concomitantly induce accelerated catabolism and clearance of $25(\mathrm{OH}) \mathrm{D}_{3}{ }^{(8,11)}$.

Differential specificities of the various cytochrome P450 (CYP) enzymes that metabolise vitamin D may also help to explain the apparent effect of ergocalciferol on $25(\mathrm{OH}) \mathrm{D}_{3}$ concentration. While the microsomal vitamin D 25-hydroxylase, CYP2R1, 25-hydroxylates both 
ergocalciferol and cholecalciferol equally well ${ }^{(29,30)}$, mitochondrial CYP27A1 25-hydroxylates cholecalciferol ${ }^{(31)}$ ', but not ergocalciferol ${ }^{(32)}$.

Another enzyme, CYP3A4, 25-hydroxylates ergocalciferol and not cholecalciferol, but also 24-hydroxylates several vitamin D metabolites ${ }^{(33-35)}$. In particular, CYP3A4 plays a major role in 23- and 24-hydroxylation of the biologically active form of cholecalciferol, 1,25-dihydroxycholecalciferol $\left(1,25(\mathrm{OH})_{2} \mathrm{D}_{3}\right)$, in the liver and small intestine ${ }^{(35)}$. CYP3A4 is the most abundant liver cytochrome $\mathrm{P} 450$ enzyme and has broad specificity, catabolising more than $50 \%$ of known drugs ${ }^{(34,36)}$. Many drugs inhibit or induce CYP3A4, thereby potentially increasing vitamin $\mathrm{D}$ turnover ${ }^{(33,35)}$. It is possible that ergocalciferol similarly induces CYP3A4, leading to enhanced 23- and 24-hydroxylation of $1,25(\mathrm{OH})_{2} \mathrm{D}_{3}$; inactivating cholecalciferol and ultimately eliminating it from the body. Thus, a plausible explanation for the inverse association between circulating $25(\mathrm{OH}) \mathrm{D}_{2}$ and $25(\mathrm{OH}) \mathrm{D}_{3}$, and any potential detrimental effect of ergocalciferol on health, is enhanced CYP3A4-induced catabolism of $1,25(\mathrm{OH})_{2} \mathrm{D}_{3}$ in the presence of ergocalciferol.

In summary, our results confirm those of previous studies that higher levels of 25(OH)D are associated with reduced mortality. For our study at least, this was due to the inverse association between $25(\mathrm{OH}) \mathrm{D}_{3}$ and mortality. Our findings with respect to $25(\mathrm{OH}) \mathrm{D}_{2}$ require confirmation in other populations with higher exposure to this form of vitamin D.

\section{Acknowledgements}

Acknowledgements: This study was made possible by the contribution of many people, including the original investigators, the Programme Manager, and the diligent team who recruited the participants and who continue working on follow-up. The authors would like to express their gratitude to the many thousands of Melbourne residents who continue to participate in the study. Participants' vital status was ascertained through the Victorian Cancer Registry (VCR) and the Australian Institute of Health and Welfare (AIHW), including the National Death Index. Financial support: Cohort recruitment was funded by VicHealth and The Cancer Council Victoria. This work was supported by the National Health and Medical Research Council (project grant 623208). A.K.H. is supported by an Australian Postgraduate Award. The funding source had no role in the design, analysis or writing of this article. Conflict of interest: None. Authorship: D.W.E. and D.R.E. made equal contributions. A.K.H. formulated the research question, conducted the literature search, analysed and interpreted the data, and wrote the first draft of the report. E.J.W. oversaw the design, statistical analysis, interpretation of the data and drafting of the report. D.K. carried out laboratory measurements of vitamin D status. A.M.H., P.R.E. and R.E.N. reviewed the manuscript. L.B. was involved in the design of the case-cohort study, obtained funding and reviewed the manuscript. G.G.G. conceived and designed the cohort study and reviewed the manuscript. D.W.E. obtained funding, oversaw measurements of vitamin D status and reviewed the manuscript. D.R.E. obtained funding, oversaw the data analysis and interpretation, and reviewed the manuscript. All authors read and approved the final manuscript. Ethics of human subject participation: This study was conducted according to the guidelines laid down in the Declaration of Helsinki and all procedures involving human subjects were approved by the Cancer Council Victoria's Human Research Ethics Committee. Written informed consent was obtained from all participants.

\section{References}

1. Chowdhury R, Kunutsor S, Vitezova A et al. (2014) Vitamin D and risk of cause specific death: systematic review and metaanalysis of observational cohort and randomised intervention studies. BMJ 348, g1903.

2. Zhang YV, Stolla M \& Kwong TC (2015) Prevalence of 25-hydroxyvitamin $\mathrm{D}_{2}$ in western New York: a 3-year study. Clin Chim Acta 444, 3-8.

3. Holick MF (2007) Vitamin D deficiency. $N$ Engl J Med 357, 266-281.

4. Tripkovic L, Lambert H, Hart K et al. (2012) Comparison of vitamin $D_{2}$ and vitamin $D_{3}$ supplementation in raising serum 25-hydroxyvitamin D status: a systematic review and metaanalysis. Am J Clin Nutr 95, 1357-1364.

5. Bjelakovic G, Gluud LL, Nikolova D et al. (2014) Vitamin D supplementation for prevention of mortality in adults. Cochrane Database Syst Rev 1, CD007470.

6. Food Standards Australia New Zealand (2015) NUTTAB 2010 - Vitamin D File. http://www.foodstandards.gov. au/science/monitoringnutrients/nutrientables/pages/default. aspx (accessed December 2015).

7. Tjellesen L, Hummer L, Christiansen C et al. (1986) Serum concentration of vitamin $\mathrm{D}$ metabolites during treatment with vitamin $\mathrm{D}_{2}$ and $\mathrm{D}_{3}$ in normal premenopausal women. Bone Miner 1, 407-413.

8. Armas LA, Hollis BW \& Heaney RP (2004) Vitamin $\mathrm{D}_{2}$ is much less effective than vitamin $\mathrm{D}_{3}$ in humans. J Clin Endocrinol Metab 89, 5387-5391.

9. Binkley N, Gemar D, Engelke J et al. (2011) Evaluation of ergocalciferol or cholecalciferol dosing, 1,600 IU daily or 50,000 IU monthly in older adults. J Clin Endocrinol Metab 96, 981-988.

10. Lehmann U, Hirche F, Stangl GI et al. (2013) Bioavailability of vitamin $\mathrm{D}_{2}$ and $\mathrm{D}_{3}$ in healthy volunteers, a randomized placebo-controlled trial. J Clin Endocrinol Metab 98, 4339-4345.

11. Logan VF, Gray AR, Peddie MC et al. (2013) Long-term vitamin $\mathrm{D}_{3}$ supplementation is more effective than vitamin $\mathrm{D}_{2}$ in maintaining serum 25-hydroxyvitamin $\mathrm{D}$ status over the winter months. Br J Nutr 109, 1082-1088.

12. Glendenning P, Chew GT, Seymour HM et al. (2009) Serum 25-hydroxyvitamin D levels in vitamin D-insufficient hip fracture patients after supplementation with ergocalciferol and cholecalciferol. Bone 45, 870-875.

13. Nimitphong H, Saetung S, Chanprasertyotin S et al. (2013) Changes in circulating 25-hydroxyvitamin $\mathrm{D}$ according to vitamin $\mathrm{D}$ binding protein genotypes after vitamin $\mathrm{D}_{3}$ or $\mathrm{D}_{2}$ supplementation. Nutr J 12, 39.

14. Giles GG (1990) The Melbourne study of diet and cancer. Proc Nutr Soc Aust 15, 61-68. 
15. Ireland P, Jolley D, Giles G et al. (1994) Development of the Melbourne FFQ: a food frequency questionnaire for use in an Australian prospective study involving an ethnically diverse cohort. Asia Pac J Clin Nutr 3, 19-31.

16. Eyles D, Anderson C, Ko P et al. (2009) A sensitive LC/MS/ MS assay of $25 \mathrm{OH}$ vitamin $\mathrm{D}_{3}$ and $25 \mathrm{OH}$ vitamin $\mathrm{D}_{2}$ in dried blood spots. Clin Chim Acta 403, 145-151.

17. Heath AK, Williamson EJ, Ebeling PR et al. (2014) Measurements of 25-hydroxyvitamin D concentrations in archived dried blood spots are reliable and accurately reflect those in plasma. J Clin Endocrinol Metab 99, 3319-3324.

18. Cox NJ (2006) Speaking Stata: in praise of trigonometric predictors. Stata J 6, 561-579.

19. Barlow WE, Ichikawa L, Rosner D et al. (1999) Analysis of case-cohort designs. J Clin Epidemiol 52, 1165-1172.

20. Nowson CA, Diamond TH, Pasco JA et al. (2004) Vitamin D in Australia. Issues and recommendations. Aust Fam Physician 33, 133-138.

21. Schöttker B, Jorde R, Peasey A et al. (2014) Vitamin D and mortality: meta-analysis of individual participant data from a large consortium of cohort studies from Europe and the United States. BMJ 348, g3656.

22. Durup D, Jørgensen HL, Christensen J et al. (2012) A reverse J-shaped association of all-cause mortality with serum 25-hydroxyvitamin D in general practice: the CopD study. $J$ Clin Endocrinol Metab 97, 2644-2652.

23. Sempos CT, Durazo-Arvizu RA, Dawson-Hughes B et al. (2013) Is there a reverse J-shaped association between 25-hydroxyvitamin D and all-cause mortality? Results from the US nationally representative NHANES. J Clin Endocrinol Metab 98, 3001-3009.

24. Michaëlsson K, Baron JA, Snellman G et al. (2010) Plasma vitamin D and mortality in older men: a community-based prospective cohort study. Am J Clin Nutr 92, 841-848.

25. Zittermann A, Iodice S, Pilz S et al. (2012) Vitamin D deficiency and mortality risk in the general population: a meta-analysis of prospective cohort studies. Am J Clin Nutr 95, 91-100.
26. Swanson CM, Nielson CM, Shrestha S et al. (2014) Higher $25(\mathrm{OH}) \mathrm{D}_{2}$ is associated with lower $25(\mathrm{OH}) \mathrm{D}_{3}$ and $1,25(\mathrm{OH})_{2} \mathrm{D}_{3}$. J Clin Endocrinol Metab 99, 2736-2744.

27. Hollis BW (1984) Comparison of equilibrium and disequilibrium assay conditions for ergocalciferol, cholecalciferol and their major metabolites. J Steroid Biochem 21, 81-86.

28. Jones KS, Assar S, Harnpanich D et al. (2014) $25(\mathrm{OH}) \mathrm{D}_{2}$ half-life is shorter than $25(\mathrm{OH}) \mathrm{D}_{3}$ half-life and is influenced by DBP concentration and genotype. J Clin Endocrinol Metab 99, 3373-3381.

29. Cheng JB, Motola DL, Mangelsdorf DJ et al. (2003) De-orphanization of cytochrome P450 2R1: a microsomal vitamin D 25-hydroxylase. J Biol Chem 278, 38084-38093.

30. Shinkyo R, Sakaki T, Kamakura M et al. (2004) Metabolism of vitamin D by human microsomal CYP2R1. Biochem Biophys Res Commun 324, 451-457.

31. Sawada N, Sakaki T, Ohta M et al. (2000) Metabolism of vitamin $\mathrm{D}_{3}$ by human CYP27A1. Biochem Biophys Res Commun 273, 977-984.

32. Guo YD, Strugnell S, Back DW et al. (1993) Transfected human liver cytochrome P-450 hydroxylates vitamin D analogs at different side-chain positions. Proc Natl Acad Sci U S A 90, 8668-8672.

33. Gupta RP, Hollis BW, Patel SB et al. (2004) CYP3A4 is a human microsomal vitamin D 25-hydroxylase. J Bone Miner Res 19, 680-688.

34. Gupta RP, He YA, Patrick KS et al. (2005) CYP3A4 is a vitamin D-24- and 25-hydroxylase: analysis of structure function by site-directed mutagenesis. J Clin Endocrinol Metab 90, 1210-1219.

35. Xu Y, Hashizume T, Shuhart MC et al. (2006) Intestinal and hepatic CYP3A4 catalyze hydroxylation of $1 \alpha, 25$-dihydroxyvitamin $\mathrm{D}_{3}$ : implications for drug-induced osteomalacia. Mol Pharmacol 69, 56-65.

36. Prosser DE, Jones G (2004) Enzymes involved in the activation and inactivation of vitamin D. Trends Biochem Sci 29, 664-673. 